08

\title{
Влияние адсорбированных молекул СО на электронное состояние нанопленок иттербия, выращиваемых на кремниевых подложках
}

\author{
(C) М.В. Кузьмин, М.А. Митцев \\ Физико-технический институт им. А.Ф. Иофрфе РАН, \\ 194021 Санкт-Петербург, Россия \\ e-mail: M.Mittsev@mail.ioffe.ru
}

Поступило в Редакцию13 фревраля 2019 г.

В окончательной редакции 13 февраля 2019 г.

Принято к публикации 13 февраля 2019 г.

Исследована адсорбция молекул монооксида углерода (СО) на нанопленках иттербия толщиной 16-200 монослоев $(6.1-76 \mathrm{~nm})$. Пленки выращены на монокристаллических кремниевых подложках с ориентацией поверхности $\mathrm{Si}$ (111). Показано, что иттербий до адсорбции молекул СО находится в двухвалентном состоянии с электронной конфигурацией $[\mathrm{Xe}] 4 f^{14} 6 s^{2}$. При адсорбции молекул газа в пленках в той их области, которая прилегает к поверхности, формируется слой, в котором иттербий трехвалентен (электронная конфигурация $\left.[\mathrm{Xe}] 4 f^{13} 5 d^{1} 6 s^{2}\right)$. Произведены оценки толщины модифицированного адсорбированными молекулами СО слоя. Эти оценки дали значения, заключенные в пределах 9-22 монослоя $(3.4-8.4 \mathrm{~nm})$.

DOI: 10.21883/JTF.2019.07.47804.47-19

\section{Введение}

В настоящее время уделяется значительное внимание изучению структур нанометрового размера $[1,2]$. В частности, довольно много работ посвящено изучению адсорбционных свойств таких структур. При этом в значительной части из них в качестве адсорбата используется монооксид углерода (угарный газ СО) [3-8]. Недостатком этих работ является то, что в них не проводилось систематическое изучение типа связи молекул СО с поверхностью нанообъектов, размерных зависимостей адсорбционных свойств последних и возможного влияния адсорбата на свойства их объема.

В отличие от только что указанных исследований в работах авторов настоящего сообщения едва ли не основное внимание уделяется изучению природы адсорбционной связи молекул с поверхностью подложек и влиянию адсорбата на свойства объема нанообъектов. Так, в работах [9-12] было показано, что молекулы CO при адсорбции на нанопленках иттербия своими двумя неподеленными электронами образуют с поверхностью подложек донорно-акцепторную связь. Было показано также, что при толщине пленок иттербия от 1 до 16 монослоев (ML) $(0.38-6.1 \mathrm{~nm})$ адсорбция молекул $\mathrm{CO}$ сопровождается его переходом из двухвалентного состояния (электронная конфигурация $[\mathrm{Xe}] 4 f^{14} 6 s^{2}$, в дальнейшем будет обозначаться $\mathrm{Yb}^{2+}$ ) в трехвалентное (конфигурация $[\mathrm{Xe}] 4 f^{13} 5 d^{1} 6 s^{2}, \mathrm{Yb}^{3+}$ ). Было показано также, что указанный переход обусловлен кулоновским взаимодействием локализованных на поверхности электронов, формирующих связь молекул с поверхностью, и электронами проводимости иттербия. Результатом этого взаимодействия является перетекание части электронов проводимости из металла в адсорбированные молекулы. Это перетекание сопровождается понижением $5 d$-уров- ня иттербия ниже уровня Ферми, т.е. переходом из двухвалентного состояния в трехвалентное.

В свете только что сказанного возникает вопрос: происходит ли уход электронов металла в молекулы (и связанный с ним валентный переход) из всего объема металла или только из ближайших к адсорбированному слою областей. Очевидно, что это - два качественно различающихся случая. Действительно, при первом из них общее количество электронов проводимости во всем объеме пленок будет плавно понижаться по мере роста количества молекул на поверхности и столь же плавно возрастать валентность от значения $2+$ до $3+$.

Во втором же случае, когда уход электронов затрагивает только ближайшие к адсорбированным молекулам слои металла, валентность в них, скорее всего, будет возрастать скачком от значения $2+$ к $3+$. Очевидно, что в этом случае толщина модифицированного адсорбированными молекулами слоя иттербия будет послойно возрастать по мере увеличения количества перетекших электронов, т.е. по мере роста адсорбционного покрытия.

Разделить рассмотренные два случая можно, если проводить исследования на нанопленках иттербия, толщина которых изменяется в широких пределах. Тогда в столь же широких пределах будет меняться общее количество электронов проводимости в пленках. Очевидно, что в первом из рассмотренных двух случаев это количество будет заметно изменяться при адсорбции молекул на тонких пленках, а на толстых пленках эти изменения будут исчезающе малыми. Сказанное означает, что валентность иттербия будет заметно изменяться при адсорбции на тонких пленках, а на толстых эти изменения будут незначительными или их не будет совсем.

Во втором же рассмотренном случае при всех толщинах нанопленок в их слоях, ближайших к поверхности, 
будет наблюдаться переход в трехвалентное состояние, индуцированный адсорбированными молекулами.

Исходя из вышесказанного, проводились исследования, результаты которых анализируются в настоящей работе. Был существенно расширен (по сравнению с предыдущими нашими работами) интервал толщин нанопленок. Вместо 1-16 ML эксперименты проводились на пленках, толщина которых изменялась от 16 до 200 ML. Предполагалось, что сопоставление полученных при этом результатов с экспериментальными данными для интервала толщин $1-16 \mathrm{ML}$ позволит установить механизм формирования модифицированного адсорбированными молекулами СО слоя иттербия.

\section{1. Методика экспериментов}

Нанопленки иттербия создавались путем его напыления на кремниевые подложки с ориентацией поверхности $\mathrm{Si}$ (111) при комнатной температуре. Иттербий наносился на поверхность подложек путем испарения его из танталовых ампул. Давление в вакуумной камере во время его испарения не превышало $3 \cdot 10^{-9}$ Torr. Скорость напыления обычно составляла $1 \mathrm{ML} / \mathrm{min}$. За $1 \mathrm{ML}$ была принята величина $7.84 \cdot 10^{14} \mathrm{~cm}^{-2}$, равная концентрации атомов $\mathrm{Si}$ на нереконструированной поверхности $\mathrm{Si}$ (111).

Исследования проводились с помощью электронной оже-спектроскопии (ЭОС), термодесорбционной спектроскопии (ТДС) и метода измерения контактной разности потенциалов, который, как известно, дает возможность измерять разность работ выхода $\Delta \varphi=\varphi_{0}-\varphi$ чистой поверхности какой-либо подложки $\left(\varphi_{0}\right)$, и работы выхода этой же подложки, покрытой тонкими пленками $(\varphi)$. Все перечисленные методы были реализованы в сверхвысоковакуумной установке с базовым давлением $4 \cdot 10^{-11}$ Torr.

Напуск газов в вакуумную камеру установки осуществлялся с помощью системы напуска после тщательной ее очистки in situ. Чистота напускаемых газов контролировалась масс-спектрометром, находившимся в непосредственной близости от исследуемых образцов. Доза напускаемого газа определялась в Лэнгмюрах: $1 \mathrm{~L}=10^{-6}$ Torr s.

Указанными выше методиками исследовались пленки иттербия до их помещения в атмосферу монооксида углерода и после этого.

\section{2. Экспериментальные результаты и их обсуждение}

Как уже указывалось, исследования были проведены для нанопленок иттербия, толщина которых была заключена в пределах 16-200 ML. Верхний предел указанного интервала определялся исходя из следующих соображений. Максимальное количество адсорбированных молекул имеет величину $\sim 10^{15} \mathrm{~cm}^{-2}$. Этой же

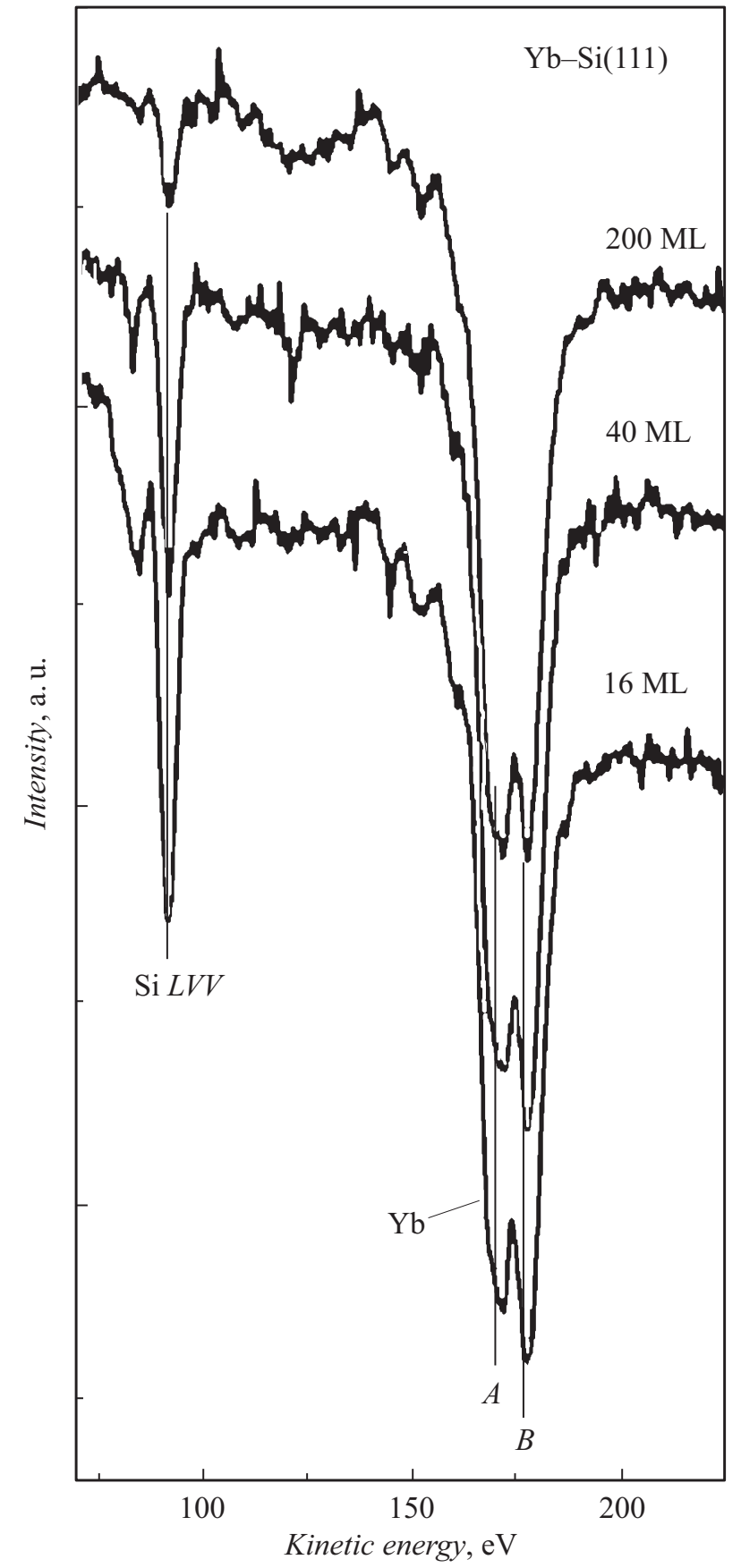

Рис. 1. Оже-спектры компонентов структур $\mathrm{Yb}-\mathrm{Si}$ (111) для трех значений толщин нанопленок иттербия: 16, 40 и $200 \mathrm{ML}$.

величине будет равно максимальное количество электронов, которое может перейти из пленок в молекулы. B нанопленках иттербия толщиной $200 \mathrm{ML}$ содержится (если использовать несколько завышенное значение количества атомов $\mathrm{Yb}$ в одном монослое $8 \cdot 10^{14} \mathrm{~cm}^{-2}$ ) $1.6 \cdot 10^{17}$ атомов $\mathrm{Yb}$, каждый из которых имеет в своей электронной оболочке два валентных электрона. Следовательно, общее количество электронов проводимости в пленках двухвалентного иттербия толщиной $200 \mathrm{ML}$ имеет величину $N \approx 3 \cdot 10^{17}$. Следовательно, для отно- 
шения максимального количества электронов $n_{\max }$, которое может перетечь из пленок в молекулы, к общему их числу справедлива оценка $n_{\max } / N \approx 3 \cdot 10^{-3}$. Это означает, что если реализуется первый из рассмотренных во введении вариантов взаимодействия адсорбированных молекул с нанопленками, то для таких пленок значение валентности будет близко к значению $2^{+}$.

На рис. 1 приведены оже-спектры нанопленок иттербия толщиной 16, 40 и $200 \mathrm{ML}$ для тех случаев, когда на поверхности нанослоев нет адсорбированных молекул СО. Видно, что в спектрах присутствуют только оже-линии иттербия и кремния. Все оже-линии имеют две особенности А и В, соотношение интенсивностей которых изменяется при увеличении толщины нанопленок от 16 до 200 ML. Как было показано в предыдущих наших работах [9], эти спектры соответствуют двухвалентному состоянию иттербия.

На спектрах рис. 1 присутствует оже-линия кремния. Значительная интенсивность этой линии обусловлена большой элементной чувствительностью кремния. На самом деле интенсивность этой линии для пленок иттербия толщиной $16 \mathrm{ML}$ составляет не более $5 \%$ от ее интенсивности для кремниевой подложки, когда на ее поверхности нет иттербия. Следует отметить, что слабая оже-линия кремния присутствует в оже-спектрах даже тогда, когда на поверхность подложки нанесено $200 \mathrm{ML}$ иттербия.

На рис. 2 приведены оже-спектры иттербия для нанопленок толщиной 16, 40 и $200 \mathrm{ML}$ для случая, когда на их поверхности адсорбированы молекулы СО (доза $480 \mathrm{~L}$ ). Из него следует, что для всех трех толщин оже-спектры, с одной стороны, качественно отличаются от аналогичных спектров чистого иттербия. А, с другой стороны, эти спектры ничем не отличаются друг от друга и полностью совпадают со спектрами, полученными ранее для пленок иттербия толщиной $1-16 \mathrm{ML}$. Это означает, что и в интервале толщин 16-200 ML адсорбция молекул CO сопровождается переходом из двухвалентного состояния $\mathrm{Yb}^{2+}$ в трехвалентное $\mathrm{Yb}^{3+}$.

Трактовка результатов, приведенных на рис. 2, зависит от того, в каком состоянии находятся молекулы СО на поверхности нанопленок иттербия. Очевидно, что возможны два варианта. В первом из них молекулы при адсорбции диссоциируют на атомы. Высвобождающиеся при этом атомы кислорода, в принципе, могут диффундировать в объем пленок, образуя при этом полуторный оксид $\mathrm{Yb}_{2} \mathrm{O}_{3}$, в котором иттербий трехвалентен.

Во втором варианте молекулы на поверхности не диссоциируют, находясь на поверхности в молекулярной форме. При этом они могут влиять на состояние нанопленок своими неподеленными электронами, с помощью которых образуется адсорбционная связь с поверхностью [9].

В настоящей работе для определения состояния молекул СО на поверхности нанопленок иттербия использовались два метода, Первый из них основан на результатах нашей работы [13]. В ней было показано, что

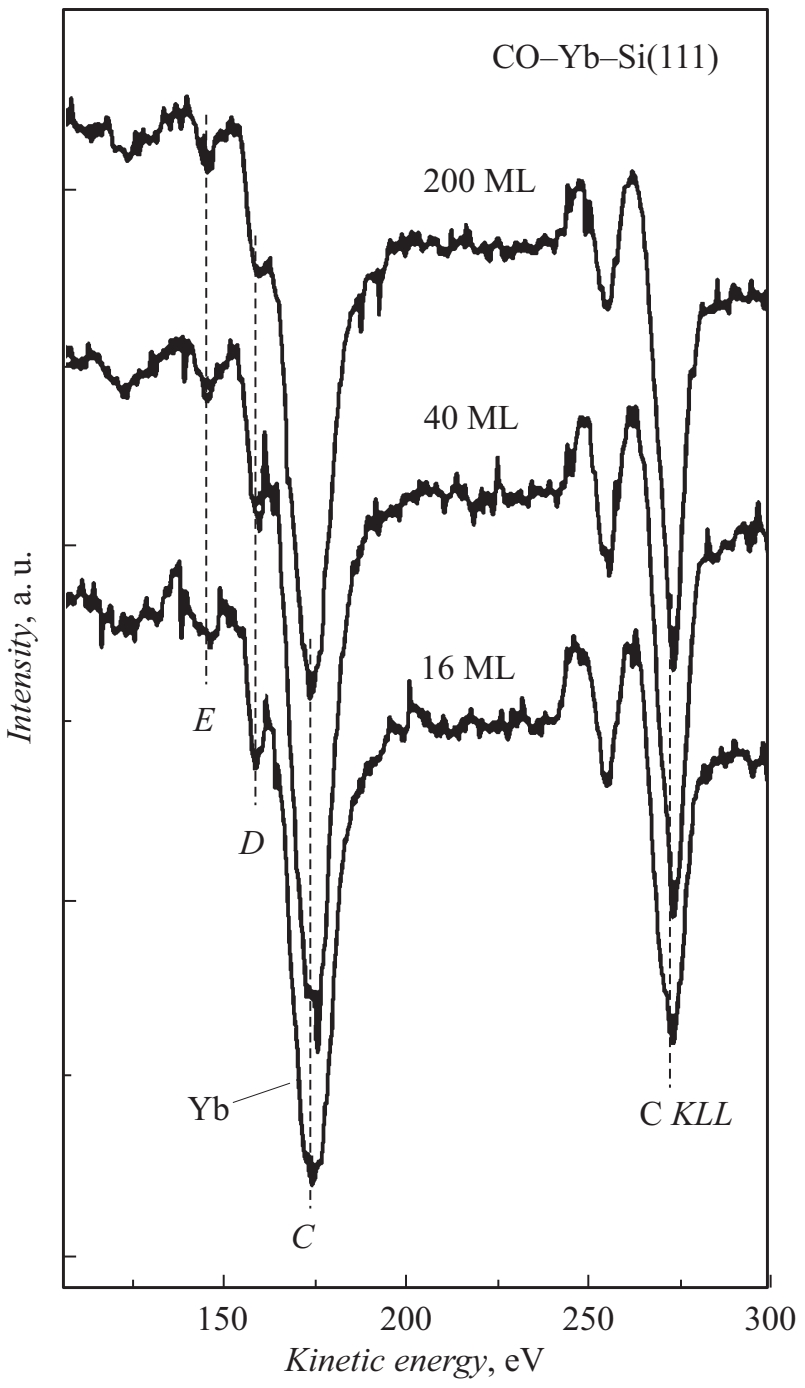

Рис. 2. Оже-спектры компонентов структур $\mathrm{CO}-\mathrm{Yb}-\mathrm{Si}$ (111) для трех значений толщины нанопленок иттербия: 16, 40 и $200 \mathrm{ML}$.

форма оже-спектров углерода качественно изменяется при диссоциации молекул $\mathrm{CO}$, которая на нанопленках иттербия происходит при температурах $T \approx 900$ К. Эти изменения показаны на рис. 3. Из этих результатов следует, что, анализируя форму оже-спектров углерода, можно получать информацию о состоянии молекул $\mathrm{CO}$ на поверхности нанопленок иттербия. В настоящей работе этим методом было показано, что на пленках иттербия толщиной $16-200 \mathrm{ML}$, так же как и на пленках ранее исследованного нами интервала толщин $1-16 \mathrm{ML}$, оже-спектры углерода имеют форму нижней кривой рис. 3. Это означает, что молекулы СО на поверхности пленок иттербия толщиной 16-200 ML находятся в молекулярной форме. Такой же вывод вытекает и из данных, полученных вторым методом. Он основан на том, что атомы углерода, высвобождающиеся при диссоциации молекул СО (если таковая происходит), при удалении иттербия с поверхности кремния прогревом 


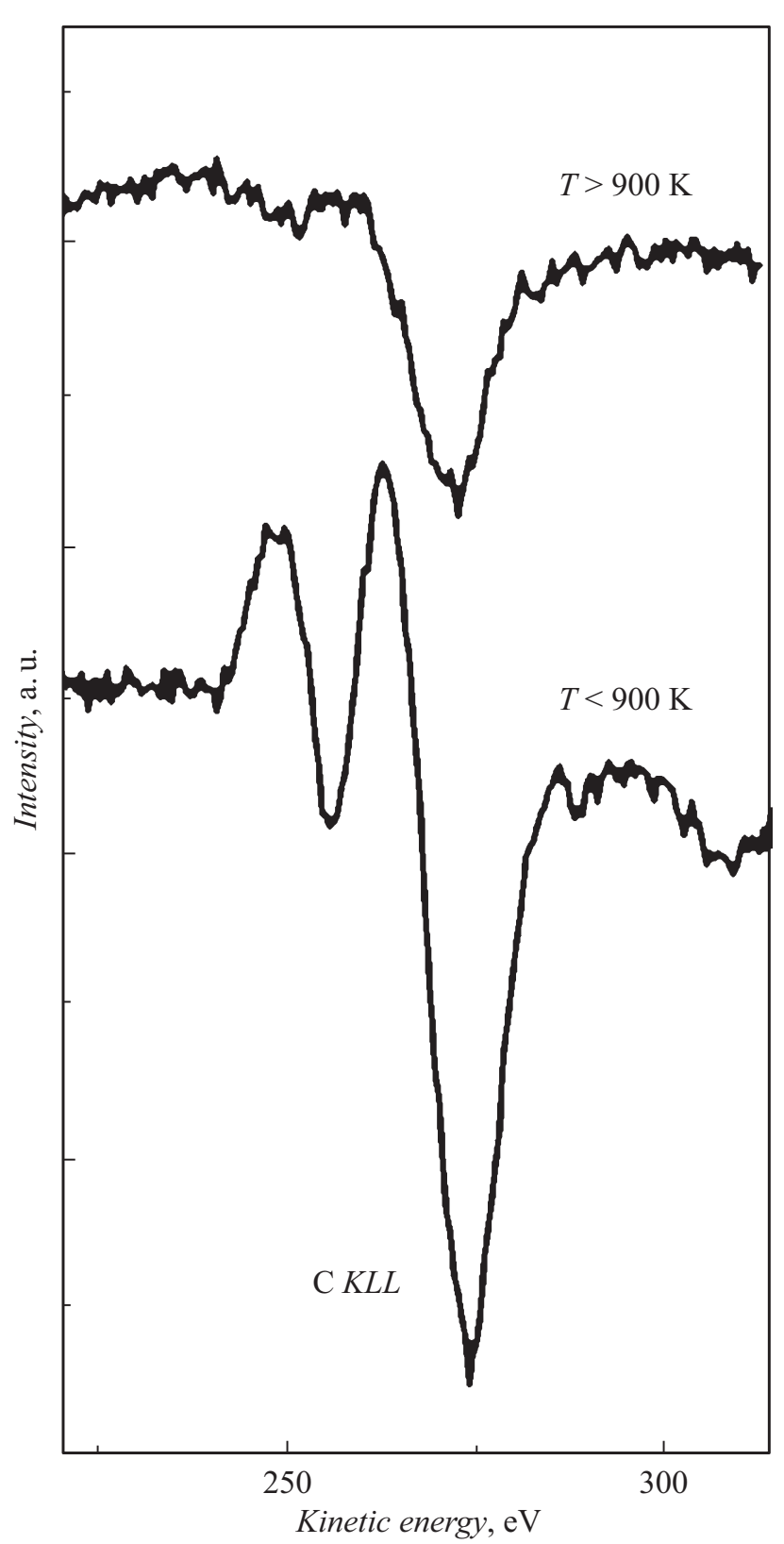

Рис. 3. Форма оже-спектров углерода $K L L(273 \mathrm{eV})$ в структурах $\mathrm{CO}(460 \mathrm{~L})-\mathrm{Yb}(16 \mathrm{ML})-\mathrm{Si}(111)$ после их прогрева до температур $T<900 \mathrm{~K}$ и $T>900 \mathrm{~K}$.

последнего не испаряются, а остаются на поверхности подложки. Это было установлено специально поставленными опытами. С помощью описанного метода было показано, что в процессе создания структур $\mathrm{CO}-\mathrm{Yb}$ на поверхности кремния, их изучения, а затем удаления с поверхности подложки быстрым прогревом накопления атомов углерода не происходит при всех толщинах нанопленок иттербия, исследованных в работе. Из этого следует, что монооксид углерода на поверхности нанопленок иттербия находится в молекулярной форме.

Все приведенные результаты дают основание считать, что механизм взаимодействия молекул СО с нанопленка- ми иттербия в интервалах их толщин $16-200$ и 1-16 ML один и тот же. Это означает, что [9-12]:

a) молекулы СО своими неподеленными электронами образуют с поверхностью пленок донорно-акцепторную связь;

б) локализованные на поверхности электроны, формирующие адсорбционную связь, кулоновскими силами взаимодействуют с электронами проводимости иттербия;

в) когда поверхностная концентрация адсорбированных молекул достигнет значительной величины, указанное электростатическое взаимодействие начинает выталкивать часть электронов проводимости из пленок в адсорбированный слой;

г) уход части электронов проводимости сопровождается понижением $5 d$-уровня ниже уровня Ферми и его заполнения в результате перехода $4 f^{14} \rightarrow 4 f^{13} 5 d^{1}$;

д) конечным результатом всех указанных процессов является переход иттербия из двухвалентного состояния $\mathrm{Yb}^{2+}$ в трехвалентное $\mathrm{Yb}^{3+}$.

Однако между ранее проведенными исследованиями и настоящей работой есть принципиальная разница. Она состоит в том, что в первом случае толщина пленок была очень мала и поэтому использованные в работах экспериментальные методы давали возможность анализировать состояние практически всех слоев пленок. Иначе обстоит дело с пленками, использованными в настоящей работе. Толщина некоторых из них (40 и $200 \mathrm{ML}$ ) существенно превосходит то ее значение, при котором экспериментальные методы дают возможность анализировать состояние пленок иттербия на всю их глубину. Однако, несмотря на это, полученные в настоящей работе экспериментальные результаты в сочетании с данными предыдущих наших работ дают возможность сформулировать соображения, касающиеся глубины, на которую распространяется стимулируемый хемосорбированными молекулами валентный переход. Это можно сделать, если использовать результаты анализа, начатого во введении настоящей работы. Согласно ему, если при осаждении молекул на поверхность нанопленки в ней происходит валентный переход, обусловленный перетеканием части электронов проводимости нанослоя в адсорбированные частицы, то в случае толстых пленок указанный переход не может охватывать весь их объем. Валентный переход будет происходить в слоях, ближайших к поверхности пленки. Судя по всему, именно такой вариант и был реализован в настоящих экспериментах. Действительно, согласно проведенным выше оценкам для пленок иттербия толщиной $200 \mathrm{ML}$, общее количество электронов, которое может перейти в адсорбированные молекулы составляет менее $0.3 \%$ от общего их числа. И, что существенно, при этом ожеспектры иттербия полностью совпадают со спектрами модифицированного иттербия для значительно более тонких пленок (менее $16 \mathrm{ML})$. Это означает, что валентный переход происходит в слое нанопленок, ближайшем к адсорбированным молекулам. Схематически это показано на рис. 4. 


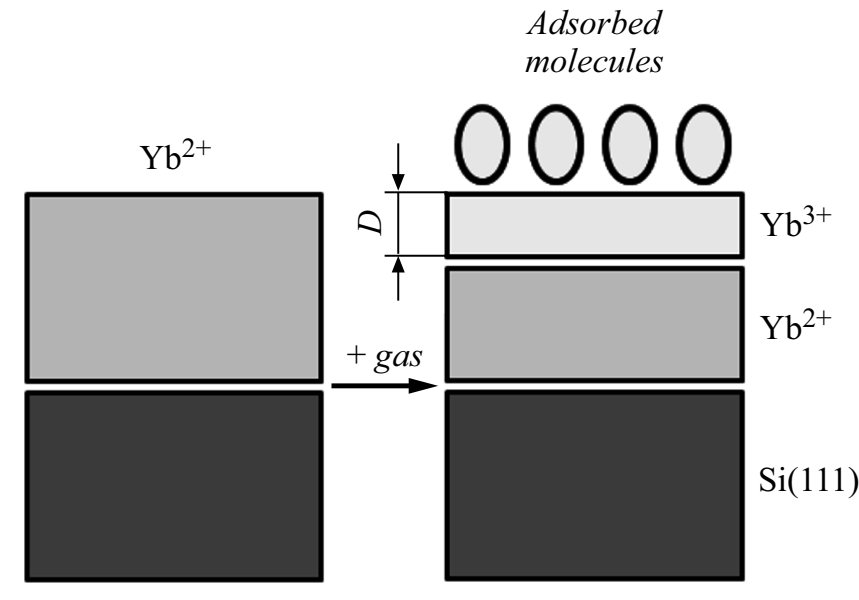

$\operatorname{Si}(111)$

Рис. 4. Перестройка пленок иттербия при адсорбции на их поверхности молекул СО.

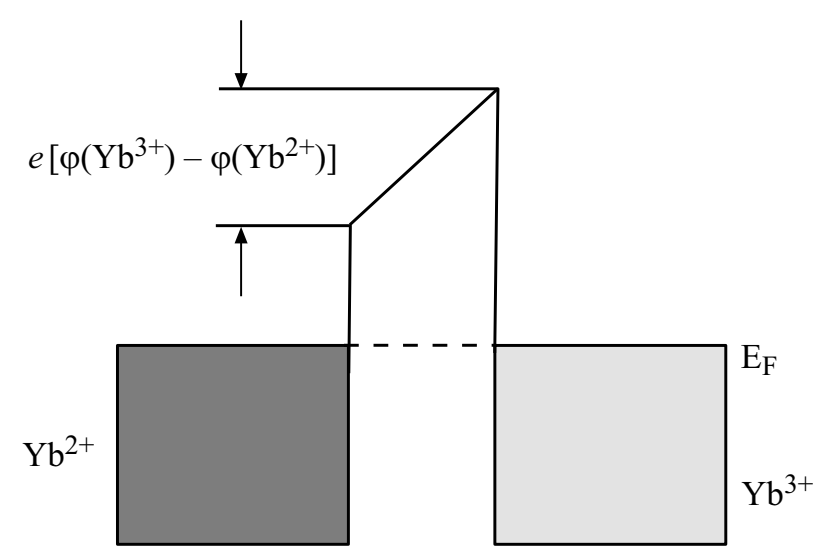

Рис. 5. Энергетическая диаграмма контакта $\mathrm{Yb}^{2+}-\mathrm{Yb}^{3+}$. Диаграмма построена в предположении, что работа выхода трехвалентного иттербия $\varphi\left(\mathrm{Yb}^{3+}\right)$ превосходит работу выхода двухвалентного иттербия $\varphi\left(\mathrm{Yb}^{2+}\right)$.

Работа выхода $\varphi$ трехвалентного иттербия неизвестна. Однако известна работа выхода трехвалентных металлов второй половины ряда редкоземельных элементов, к которой принадлежит иттербий. Она на $0.5-0.65 \mathrm{eV}$ превышает работу выхода двухвалентного иттербия [14]. Если для разности $\varphi\left(\mathrm{Yb}^{3+}\right)-\varphi\left(\mathrm{Yb}^{2+}\right)$ справедлива такая же величина, то тогда при адсорбции молекул $\mathrm{CO}$, в результате которой формируется слой модифицированного иттербия, внутри нанопленки на границе раздела двух- и трехвалентного иттербия образуется потенциальный барьер, показанный на рис. 5.

Толщина $D$ модифицированного адсорбированными молекулами слоя иттербия (рис. 4) не может быть определена с помощью использованных в настоящей работе экспериментальных методов. Однако она может быть оценена с помощью расчетов максимальной глубины выхода оже-электронов, которые еще могут давать заметный вклад в форму и интенсивность регистрируе- мых экспериментально оже-линий. Очевидно, что если на этой максимальной глубине в экспериментальных оже-спектрах будут отсутствовать особенности, присущие двухвалентному иттербию, то она и будет равна минимальной толщине модифицированного адсорбированными молекулами слоя иттербия. Для проведения указанных расчетов необходимо знать величину длины свободного пробега электронов $\lambda$. Эта величина может быть получена из универсальной зависимости длины свободного пробега электронов от их энергии [15]. Для иттербия (энергия $175 \mathrm{eV}$ ) она равна $6.7 \AA$. Такое же значение было получено теоретическими расчетами в работе [16]. Существенно большее значение длины свободного пробега оже-электронов иттербия приводится в работе [17]: $\lambda=5.6 a$, где $a-$ толщина монослоя (для иттербия $a=3.8 \AA$ ). В первом случае, когда $\lambda=6.7 \AA$, максимальная глубина выхода равна 9 монослоям иттербия или $3.4 \mathrm{~nm}$, во втором случае, когда $\lambda=5.6 a-$ 22 монослоям, или $8.3 \mathrm{~nm}$. Разброс значений большой. Однако, несмотря на это, из проведенных оценок минимальной толщины модифицированного слоя иттербия следует, что эта величина значительна.

\section{3. Заключение}

Комплексом экспериментальных методов исследована адсорбция молекул СО на нанопленках иттербия толщиной 16-200 монослоев $(6.1-76 \mathrm{~nm})$. Пленки выращивались на монокристаллических кремниевых подложках с ориентацией поверхности $\mathrm{Si}$ (111). Показано, что адсорбированные на поверхности нанопленок молекулы находятся в молекулярной форме. Показано также, что иттербий до адсорбции молекул СО находится в двухвалентном состоянии с электронной конфигурацией $[\mathrm{Xe}] 4 f^{14} 6 s^{2}$. При адсорбции молекул газа в пленках в той их области, которая прилегает к поверхности, формируется слой, в котором иттербий трехвалентен (электронная конфигурация $[\mathrm{Xe}] 4 f^{13} 5 d^{1} 6 s^{2}$ ). Произведены оценки минимального значения толщины модифицированного адсорбированными молекулами СО слоя. Эти оценки дали значение, заключенное в пределах 9-22 монослоя (3.4-8.4 nm).

\section{Конфликт интересов}

Авторы статьи конфликта интересов не имеют.

\section{Список литературы}

[1] Шикин А.М. Формирование, электронная структура и свойства низкоразмерных структур на основе металлов. СПб.: ВВМ, 2011. $432 \mathrm{c}$.

[2] Cao G., Wang Y. Nanostructures and Nanomaterials: Synthesis, Properties, and Applications. Vol. 2. World Scientific, 2011. 596 p. DOI: $10.1142 / 7885$

[3] Yang B., Lin X., Gao H.-J., Nilius N., Freund H.-J. // J. Phys. Chem. C. 2010. Vol. 114. N 19. P. 8997-9001. DOI: $10.1021 / \mathrm{jp} 100757 \mathrm{y}$. 
[4] Zhu L., Zhang L., Virkar A.V. // J. Electrochem. Soc. 2018. Vol. 165. N 3. P. F232-F237. DOI: 10.1149/2.0011805jes

[5] Qin Z.-H., Lewandowski M., Sun Y.-N., Shaikhutdinov S., Freund H.-J. // J. Phys. Condens. Mat. 2009. Vol. 21. P. 134019. DOI: $10.1088 / 0953-8984 / 21 / 13 / 134019$

[6] Wilson E.L., Chen Q., Brown W.A., Thornton G. // J. Phys. Chem. C. 2007. Vol. 111. P. 14215-14222.

[7] Jakob P., Schlapka A. // Surf. Sci. 2007. Vol. 601. P. 3556-3568. DOI: 10.1016/j.susc.2007.06.035

[8] Voigts F., Bebensee F., Dahle S., Volgmann K., MausFriedrichs $W$. // Surf. Sci. 2009. Vol. 603. P. 40-49. DOI: $10.1016 /$ j.susc.2008.10.016

[9] Кузьмин М.В., Митцев М.А. // ФТТ. 2010. Т. 52. Вып. 3. C. $577-584$.

[10] Бутурович Д.В., Кузьмин М.В., Логинов М.В., Митцев М.А. // ФТТ. 2015. Т. 57. Вып. 9. С. 1822-1829.

[11] Митцев М.А., Кузьмин М.В., Логинов М.В. // ФТТ. 2016. Т. 58. Вып. 10. С. 2054-2058.

[12] Митцев М.А., Кузьмин М.В. // ФТТ. 2018. Т. 60. Вып. 7. C. 141-1422. DOI: 10.21883/FTT.2018.07.46133.024

[13] Кузьмин М.В., Митцев М.А. // ФТТ. 2011. Т. 53. Вып. 6. C. $1224-1229$.

[14] Самсонов Г.В. Свойства элементов. Ч. 1. Физические свойства. Справочник. 2-е изд. М.: Металлургия, 1976. $599 \mathrm{c}$.

[15] Фелдман Л., Майер Д. Основы анализа поверхности и тонких пленок / Пер с англ. М.: Мир, 1980. 342 с.

[16] Powell C.J., Jablonski A. NIST Electron Inelastic-Mean-FreePath Database. Version 1.2, SRD 71. National Institute of Standards and Technology, Gaithersburg, MD. 2010.

[17] Gerken F., Barth J., Kammerer R., Johansson L.I., Flodström A. // Surf. Sci. 1982. Vol. 117. P. 468-474. 